\title{
Acculturation and Self-rated Health Among Asian Immigrants: The Role of Gender and Age
}

\author{
Min Ju Kim ${ }^{1}$ (D) Bridget K. Gorman ${ }^{1}$
}

Received: 10 August 2020 / Accepted: 25 January 2021 / Published online: 20 February 2021

(c) The Author(s) 2021

\begin{abstract}
Using the 2002-2003 National Latino and Asian American Study (NLAAS), we examine the relationship between acculturation and poor-to-fair self-rated health (SRH) among Asian immigrants $(N=1639)$. Using latent class analysis, we construct a multidimensional measure of acculturation that considers dimensions of involvement in U.S. culture as well as attachment to Asian ethnic cultures and identify three classes of Asian immigrants: the assimilated, who most strongly adhere to U.S. culture; the integrated, who align with both U.S. and Asian ethnic cultures; and the separated, who are almost exclusively attached to Asian ethnic cultures. Logistic regression results revealed that among the pooled sample of Asian immigrant adults, the separated are significantly more likely to report poor-to-fair SRH than the assimilated. We then tested for gender and age differences in the acculturationSRH relationship, and found that stratifying by gender yields noticeably different patterns. Among Asian immigrant women, the probability of reporting poor-to-fair SRH increases with age for the separated and the integrated, while it declines with age for the assimilated. Conversely, among Asian immigrant men, the probability of reporting poor-to-fair SRH increases most steeply with age for the assimilated, while it is shallower for the separated and the integrated. Future research should continue to develop a dynamic understanding of acculturation and examine its association with other health outcomes, including how these relationships differ across subsets of immigrant groups.
\end{abstract}

Keywords Acculturation · Self-rated health $\cdot$ Immigrant $\cdot$ Asian $\cdot$ Gender $\cdot$ Age

Min Ju Kim

Min.Ju.Kim@rice.edu

1 Department of Sociology, Rice University, Houston, TX, USA 


\section{Introduction}

Asians are now the fastest growing racial minority population in the United States, with a growth rate of $72 \%$ from 2000 to 2015 , reflecting a rise from 11.9 million to 20.4 million people (Pew Research Center 2017). This outpaced the growth rate of $60 \%$ among Hispanics during the same period. Immigration contributed substantially to the growth of the Asian American population, as a high proportion (59\%) is foreign born (Pew Research Center 2017). This trend will likely continue in the years ahead, since migrants from Asia were the largest immigrant group arriving in the U.S. between 2010 and 2017 (National Geographic 2018).

Given their growing numbers in the U.S., understanding how acculturation status shapes well-being among Asian immigrants is increasingly important. To date, however, most research on acculturation among Asian immigrants, particularly in areas related to health, has utilized one-sided proxies (e.g., duration of U.S. residence) that only gauge their involvement in U.S. culture. In order to more accurately examine acculturation among Asian immigrants, multidimensional measurement is needed that not only reflects involvement in U.S. culture but also attachment to Asian cultures based on their ethnic heritage. As such, we follow the work of Berry (2003) and classify Asian immigrants into selective groups (assimilated, integrated, separated) based on two dimensions that respectively measure involvement in U.S. culture (as exhibited through duration of U.S. residence and English proficiency) and orientation toward Asian ethnic cultures (as demonstrated by level of ethnic attachment and native-language proficiency). By employing a multidimensional perspective, we aim to provide a more enriched understanding of acculturation and its relationship to health status among Asian immigrants.

Furthermore, while much research in relation to acculturation and health among Asian immigrants has investigated aspects of acculturative stress (Tummala-Narra et al. 2012; Xu and Chi 2013) and mental health outcomes such as psychological distress (Chung and Epstein 2014), relatively less research has been conducted on their physical health. Our analysis examines self-rated physical health, based on findings from existing research that self-rated health is a strong predictor of various health outcomes including coronary heart disease and cardiovascular disease (Jonnalagadda and Diwan 2005; May et al. 2006), stroke (Emmelin et al. 2003; Jonnalagadda and Diwan 2005), and most notably, mortality (Ferraro and Kelley-Moore 2001; Idler et al. 2004; Shadbolt et al. 2002) as well as health behaviors like smoking, alcohol consumption, and physical activity (Tran et al. 2013). In addition, we give attention to the moderating role of age and gender differences in the relationship between acculturation and self-rated physical health. Age is expected to play a key role as a moderator in that it functions as a crucial yardstick with which individuals evaluate their health, either through age-specific conditions or comparison with cohorts (Jylhä 2009). It is also important in that many elderly Asian immigrants tend to be less U.S. acculturated than their younger counterparts (Mui and Kang 2006; Tsoh et al. 2016), a difference 
that is likely to surface in the association between acculturation and self-rated physical health. Previous studies have also documented significant gender differences in the associations between acculturation and health (Gorman et al. 2014; Leu et al. 2011), and so we further consider whether the relationship between acculturation and self-rated health differs for men and women among Asian immigrants.

To explore these relationships, we draw on data collected among Asian immigrants in the 2002-2003 National Latino and Asian American Study (NLAAS), and investigate two related questions. First, how is acculturation associated with self-rated physical health among Asian immigrant adults in the United States? Second, do gender and age shape the associations between acculturation and self-rated health? We first examine how self-rated physical health varies across three different acculturation groups (the assimilated, integrated, and separated) among the pooled sample, and test for the moderating role of age. Then, we examine the same relationships separately for men and women, to evaluate gender-specific differences in how acculturation is associated with self-rated physical health. Considering the rapidly increasing population of Asians in the U.S., including those who are foreign born, examining how acculturation, in varying forms, is associated with their health status across gender and age groups is a significant contribution to public health knowledge.

\section{Literature Review}

\section{Acculturation as a Multidimensional Construct}

Acculturation can be broadly defined as all changes that arise as a consequence of contact between individuals and groups of different cultural backgrounds (Berry and Sam 2016). However, because acculturation is not merely about the amount of contact that individuals come to have with the host society, acculturation should be conceptualized as multilinear or multidimensional, reflecting the interplay between cultures of both the host society and the native country (Berry 2003). In recognition of such reciprocity, a typology of acculturation has been proposed that simultaneously takes into account orientations toward the host society and the native country (Berry 1970; Sommerlad and Berry 1970). According to this typology, four strategies of acculturation exist: assimilation, separation, integration, and marginalization.

The strategy of assimilation is utilized by those who do not wish to maintain their native-country cultural identity and only interact with the culture of the host society. From the viewpoint of the larger society, utilization of this strategy reinforces the conception of a melting pot, which can be described as the blending of cultures and eventual disappearance of division by race/ethnicity (Hirschman 1983). In contrast, a separation strategy is employed by those who seek to only adhere to their original cultural identity and avoid interaction with others of the host society. This strategy is understood as a form of societal-level segregation. The third strategy, integration, is used by those who simultaneously maintain their native-country cultural identity and actively interact with members of the host society. The sense 
of cultural integrity characterizes this third strategy. From the point of the larger society, utilization of this strategy fosters multiculturalism. Lastly, the strategy of marginalization is exercised by those who have little motivation for either maintaining their original cultural identity or interacting with others of the host society. It is important to note that the employment of this strategy may not be voluntary. In fact, it is highly probable that experiences of discrimination and failed attempts at assimilation underlie resort to this strategy. At the societal level, this strategy is understood as exclusion.

Thus, cultures of the host society and the native country are not as mutually exclusive as conventional understandings of acculturation propose. The fact that culture can be operationalized in many ways such as participation in activities, adoption of traits, or identification with certain groups (Snauwaert et al. 2003) implies that one's cultural identity may encompass more than one dimension and that individuals may selectively adopt traits or behaviors that they deem advantageous (Abraído-Lanza et al. 2006). Therefore, instead of employing a unidirectional, single-dimension standpoint, a multilinear and multidimensional approach to acculturation must be utilized in order to more accurately measure acculturation and its relation to health status (for other examples, see Berry and Sabatier 2010; Costigan and Koryzma 2011; Hwang and Ting 2008; Schwartz and Zamboanga 2008; Torres et al. 2012). With the latter approach, the nuances of acculturation that range from language, food, music preferences, extent of co-ethnic social ties and contacts, ethnic identification, and ethnic social affiliation can be more effectively captured (Abraído-Lanza et al. 2006). Furthermore, the varied contexts of acculturation that depend on the different histories, policies, and social structures of immigrant groups can also be reflected. In addition, because it does not posit white middle-class values as the ultimate standard, acculturation to diverse cultures that exist in the host society becomes possible.

\section{Acculturation and Health Among Asian Immigrants}

In general, acculturation among Asian immigrants is understood as a stressful and negative process that impacts their health and health behavior. Acculturative stress has been identified as a factor significantly associated with mental health outcomes such as depressive symptoms (Tummala-Narra et al. 2012; Xu and Chi 2013), psychological distress (Chung and Epstein 2014), and even visual and auditory hallucinations (DeVylder et al. 2013). Studies that have utilized proxy measures to gauge levels of acculturation have found that limited English proficiency is an important barrier to health service use (Bauer et al. 2010; Kang et al. 2010). While proficiency and preference have been interchangeably used in health, Gee et al. (2010) show that English proficiency is a robust indicator consistently associated with improved health among Asian immigrants whereas language preference is highly sensitive to model specification. Increased duration in the U.S. was associated with increased prevalence and frequency of smoking (Gorman et al. 2014), particularly among women (An et al. 2008). Both greater English proficiency and longer duration in the U.S. were identified as 
strong predictors of alcohol consumption, although specific patterns varied by ethnicity (Park et al. 2014). Findings on weight tend to be relatively inconsistent, with either a positive (Choi 2012; Lauderdale and Rathouz 2000; Singh and Lin 2013) or a nonsignificant (Gorman et al. 2016; Park et al. 2008) association with duration in the U.S.

Reports of self-rated health among Asian immigrants likewise vary. On the one hand, studies have demonstrated that acculturation to the U.S. culture is generally negatively associated with self-rated health (Alang et al. 2015; Lee et al. 2013; Lommel and Chen 2016). Longer duration in the U.S. has been found to be associated with worse self-rated health, with thresholds under which immigrants reported better self-rated health (Frisbie et al. 2001; Gong et al. 2012). Particularly among the first generation, Asian immigrants with longer duration of residence had greater odds of reporting poor-to-fair self-rated health compared to those with less years of duration (Acevedo-Garcia et al. 2010).

Conversely, other studies have documented a positive relationship between acculturation and self-rated health. Chou et al. (2010) found that Chinese immigrants with longer duration in the U.S. actually reported lower odds of poor-tofair self-rated health, relative to those with shorter duration. Taking into account differences by cohort, Ro et al. (2015) showed that among older cohorts, selfrated health improved with longer duration in the U.S. In a similar vein, bicultural Asian immigrants reported the best self-rated mental health, while recently arrived immigrants reported the worst (Bulut and Gayman 2016). Kimbro et al. (2012) have likewise found that bilingual Asian immigrants had both better selfrated physical health and mental health than native-language or English-dominant immigrants.

While studies examining the relationship between acculturation and self-rated health among Asian immigrants demonstrate contradictory findings, those from studies that focus specifically on older immigrants are more consistent, with English proficiency and age at migration serving as particularly important predictors. Poor proficiency in speaking English was associated with poor self-rated health among elderly Chinese immigrants, even after controlling for access to health care services (Tsoh et al. 2016). Older Asian immigrants with limited English proficiency reported poorer self-rated health and greater psychological distress than their bilingual and English-only counterparts, as well as limited utilization of health services and more barriers to health service use (Kim et al. 2011). While no significant association has been observed for self-rated mental health, Lam et al. (2012) found that older Asian immigrants who immigrated to the U.S. later in life reported the poorest self-rated physical health. Among the few studies on Asian immigrants that have employed a multidimensional approach to acculturation, outcomes have leaned toward mental health such as psychological adjustment (Costigan and Koryzma 2011), psychological distress and depression (Hwang and Ting 2008), and self-rated mental health (Bulut and Gayman 2016). Our study addresses this gap by focusing on self-rated physical health among Asian immigrants with a multidimensional framework of acculturation. 


\section{Gender, Age, and Asian Migrant Health}

Associations between acculturation and health among Asian immigrants reveal gendered patterns that signal different processes of cultural adaptation among men and women. In general, acculturation to U.S. culture is understood as a factor that particularly has a negative impact on the health of women (Lopez-Gonzalez et al. 2005). For instance, while levels of U.S. acculturation inversely measured through nativelanguage proficiency and preference for ethnic food were negatively associated with smoking among men, it was the reverse for women with more U.S. acculturated women reporting greater smoking rates (Ma et al. 2004). Gorman et al. (2014) demonstrate more gender-specific findings with varied measures of acculturation. While aspects of acculturation such as age at migration, duration of U.S. residence, and native-language proficiency were significant predictors of smoking frequency among women, factors such as U.S. citizenship, English proficiency, and frequency of return visits to native country were significant only among men, implying the need to parse out different dimensions of acculturation. The association between acculturation and weight-related health also appears to be dependent on gender. Men were not only more likely to be acculturated and overweight than women, but the association between American fast food consumption and overweight also existed only among men (Jasti et al. 2011). Gorman et al. (2016), although contrary, likewise report gender-dependent associations between acculturation and weight, with more frequent visits to native country being positively associated with overweight only among men. In relation to mental health, Leu et al. (2011) not only show that significant predictors of mental health vary by gender, but also reveal that the strength of the associations depends on levels of acculturation within each gender. Specifically, a negative relationship between family cultural conflict and mental health was identified among women, and the association was stronger among those with greater ethnic identification. For men, a negative association between everyday discrimination and mental health was identified that was stronger among those with poorer English proficiency.

In addition to gender, age is another factor that likely shapes the relationship between acculturation and health among Asian immigrants, considering that elderly Asian immigrants tend to remain culturally isolated. Previous studies have demonstrated that family is the most prominent source from which Asian immigrants derive varying types of support, ranging from financial aid, information, and advice to emotional companionship (Wong et al. 2005). This tendency stands out among elderly Asian immigrants with strong reliance on their adult children (Lubben and Becerra 1987; Wong et al. 2005), reflecting not only greater prevalence of intergenerational households among Asians than among non-Hispanic whites (Chappell 2003) but also strong attachment to traditional values such as filial piety (Kim et al. 1991), as well as high rates of linguistic isolation (Wong et al. 2007). Unfortunately, such separation from mainstream society and low levels of U.S. acculturation can result in negative health outcomes. According to Zhang (2012), while family cultural conflict, negative interaction with relatives, and negative interaction with friends were all associated with psychological distress, the adverse impact of family cultural conflict was greater among those with poor-to fair English proficiency. 
Mui and Kang (2006) have similarly found that received assistance from adult children, together with longer duration in the U.S., was actually a significant predictor of depression among elderly Asian immigrants.

Taking into account such findings from the existing literature, we first hypothesize that the separated (Berry 1970; Sommerlad and Berry 1970) will be most likely to report poor-to-fair self-rated physical health among the pooled sample of Asian immigrant adults, and that the association will become stronger with age. Second, considering the particularly negative impacts of U.S. acculturation on women's health, we expect that assimilated Asian immigrant women will be most likely to report poor-to-fair self-rated physical health, while for men, no a priori expectations are made.

\section{Data/Methods}

\section{Data}

We examine data from the 2002 to 2003 National Latino and Asian American Study (NLAAS), a nationally representative community household survey designed to measure mental and physical health and healthcare access among Latin and Asian Americans aged 18 and over residing in the United States, with the exclusion of institutionalized and military-based populations. A strength of the NLAAS is that it includes a wide range of acculturation measures, both toward the U.S. and country of origin. A total of 4649 interviews were completed, drawn using a four-stage national area probability sample with special supplements for adults of Puerto Rican, Cuban, Chinese, Filipino, and Vietnamese origin. This included 2095 respondents who identified as Asian American. For this study, the analytic sample is restricted to 1639 foreign-born Asians who have valid information on self-rated physical health (868 women and 771 men).

\section{Measures}

\section{Dependent Variable}

Our dependent variable is a dichotomous measure of poor or fair self-rated physical health. In the original questionnaire, respondents were asked to rate their overall physical health on a five-point scale (excellent, very good, good, fair, or poor). We created a dichotomous measure with respondents classified as $1=$ poor or fair self-rated physical health, and $0=$ good, very good, or excellent self-rated physical health. We focus on a dichotomous version of self-rated health to examine the conditions that result in the most problematic outcome from a health standpoint. Numerous studies similarly dichotomize self-rated health to focus on group differences in those who rate their health as poor or fair (e.g., Veenstra 2011), including those focused on immigrants (Acevedo-Garcia et al. 2010) and Asian immigrants (John et al. 2012). Studies also consistently show that disease prevalence is associated 
with poorer self-rated health (Wu et al. 2013). While we acknowledge that our analyses are limited to self-rated health that is dependent on contexts of evaluation such as cultural and historical interpretations of health (Jylhä 2009), we rely on its utility as a strong predictor of major physical conditions like heart disease (Emmelin et al. 2003; Jonnalagadda and Diwan 2005; May et al. 2006) and mortality (Ferraro and Kelley-Moore 2001).

\section{Independent Variable}

Our main predictor of interest is acculturation. Theoretically drawing from discussions of multidimensionality of acculturation (Berry 1970, 2003), we created an acculturation measure based on four criteria: duration of U.S. residence (from $<5$ years to more than 20 years), English proficiency (average score across reading, writing, and speaking English with Cronbach's alpha of .97; ranges from 1 to 4), ethnic attachment (average score across three measures with Cronbach's alpha of .75: identification with people of same racial and ethnic descent, feelings of closeness to people of same racial and ethnic descent, and amount of time intended to be spent with people of same racial and ethnic descent; ranges from 1 to 4), and native-language proficiency (average score across reading, writing, and speaking native language with Cronbach's alpha of .92; ranges from 1 to 4 ). It is important to note here that our choice of English (and native language) proficiency over language preference was based on the fact that the former is a consistently robust predictor of self-rated physical health whereas the latter is relatively unreliable and dependent on model specification. According to Gee et al. (2010), language preference has more room to introduce bias stemming from the political dynamics embedded in language use and respondent's interpretation of them when asked about preference. Therefore, we selected language proficiency over preference in order to yield more accurate and consistent findings as it relates to self-rated physical health.

We conducted latent class analysis to obtain our acculturation measure. Latent class analysis is an inductive clustering method that classifies objects similar in their observation values to the same class, the 'latent class,' based on identified patterns or selected criteria (Magidson and Vermunt 2004). We conducted the analysis with a priori categorization of three classes: the assimilated, the integrated, and the separated (Berry 2003). The assimilated refers to Asian immigrants that more strongly adhere to the culture of the receiving (U.S.) society and show evidence of detachment from the culture of the sending society. The separated refers to those that are the reverse, with strong attachment to their culture of origin and evidence of avoidance of interaction with the culture of the receiving society. Last, the integrated are an immigrant group that is distinctive from both the assimilated and the separated in that they strongly adhere to the culture of the receiving society while simultaneously maintaining strong ties to the culture of the sending society.

\section{Covariates}

We adjust for a series of demographic, socioeconomic, and psychosocial characteristics (see Table 2 for specific sample characteristics). Demographic characteristics 
include age (range 18-95), marital status, family size (range 1-7), and ethnic identity (Chinese, Filipino, Vietnamese, and other Asian groups). For socioeconomic status, we include measures of years of completed schooling, employment status, and Census 2001 income-to-poverty index.

To control for psychosocial characteristics, we included several stress and support measures. Level of acculturative stress was measured as a summed score of nine dichotomous (yes/no) items such as 'Do you feel guilty for leaving family or friends in your country of origin?' and 'Do you feel that in the United States you have the respect you had in your country of origin?' Levels of family cohesion and family cultural conflict were likewise measured as a summed score of ten and five items each. Items for family cohesion range from 1 ('strongly disagree') to 4 ('strongly agree'), to statements such as 'Family members respect one another.' For level of family cultural conflict, item response categories ranged from 1 ('hardly ever or never') to 3 ('often'), to statements such as 'You have felt that being too close to your family interfered with your own goals.' We account for support from relatives using three measures: frequency of talking to relatives (ranging from $1=$ 'less than once a month' and $5=$ 'most every day'), feelings of opening up to discuss worries with relatives $(1=$ 'not at all' to $4=$ 'a lot'), and feelings of reliance on relatives ( $1=$ 'not at all' to $4=$ 'a lot'). We also created a dichotomous measure of frequent attendance at religious services. Respondents were asked, 'How often do you usually attend religious services?', which ranged from 1 ('more than once a week') to 5 ('never'); we constructed a dichotomous measure to reflect those who attend at least once a week $(1=$ more than once a week/about once a week, and $0=$ one to three times a month/less than once a month/never).

\section{Statistical Analysis}

We use logistic regression to predict poor-to-fair self-rated health. All analyses are stratified by gender ${ }^{1}$ and weighed to represent the non-institutionalized Asian immigrant population in the United States. We also use the 'svy' command in Stata to estimate Taylor linearized standard errors to account for the complex sampling frame of the NLAAS. All missing data were multiply imputed using chained equations in Stata 16.0.

\footnotetext{
${ }^{1}$ We also test for the moderating role of age in our models. In addition, please note that we explored whether ethnic identity operated as a moderator for acculturation, but supplemental tests (not shown) indicated that the relationship between acculturation status and self-rated physical health did not differ significantly across Asian ethnic subgroups.
} 
Table 1 Components of acculturation status measure

\begin{tabular}{llll}
\hline \multicolumn{2}{l}{ Acculturation status } & \\
\cline { 2 - 4 } & $\begin{array}{l}\text { Class 1 } \\
\text { (Assimilated) }\end{array}$ & $\begin{array}{l}\text { Class 2 } \\
\text { (Integrated) }\end{array}$ & $\begin{array}{l}\text { Class 3 } \\
\text { (Separated) }\end{array}$ \\
\hline Duration of U.S. residence, $\%$ & & .18 \\
$\quad<5$ years & .04 & .22 & .24 \\
5-10 years & .04 & .14 & .33 \\
11-20 years & .40 & .33 & .24 \\
More than 20 years & .52 & .30 & 1.55 \\
English proficiency, mean & 3.48 & 3.22 & 3.37 \\
Ethnic attachment, mean & 2.91 & 3.34 & 3.13 \\
Native language proficiency, mean & 1.69 & 3.69 & 680 \\
Sample size & 241 & 718 & \\
\hline
\end{tabular}

\section{Results}

\section{Sample Characteristics}

Table 1 displays the percentage distribution and mean values for each component of our acculturation measure across the three classes. Class 1 is composed of the 'assimilated,' who have stayed long in the United States with high fluency in English, while degree of ethnic attachment and native-language proficiency are low: 92\% have lived in the United States for 11 or more years, and English proficiency is the highest (3.48 out of 4.0), but ethnic attachment and native-language proficiency are the lowest among the three classes with a score of 2.91 and 1.69, respectively. Class 2 is composed of the 'integrated,' who have stayed long in the United States with fluency in English, at the same time being strongly attached to their ethnic groups and exhibiting fluency in native language: $63 \%$ have lived in the United States for 11 or more years, English proficiency is high with 3.22 out of 4.0, and ethnic attachment and native-language proficiency are also high with scores of 3.34 and 3.69. Last, class 3 includes those who are 'separated', who have stayed long in the United States but show little fluency in English, strong attachment to their ethnic groups and fluency in their native language: $57 \%$ have lived in the United States for 11 or more years, but English proficiency is the lowest among the three classes with a score of 1.55 out of 4.0, while score for ethnic attachment is the highest with 3.37 out of 4.0 and also high for native-language proficiency with a score of 3.13.

Table 2 presents weighted sample characteristics for foreign-born Asian adults, stratified by acculturation status and gender. It shows that poor-to-fair self-rated physical health rates are substantially elevated among the separated, for both women (36\%) and men (25\%). Poor-to-fair SRH is lowest among the integrated, for both women (9\%) and men (7\%). Additionally, while among women, we see similarity in poor-to-fair SRH among the assimilated (10\%) and integrated (9\%), for men, those who are integrated report half the rate of poor-to-fair SRH compared to those who are assimilated (7\% vs. $14 \%$, respectively). 
Table 2 Weighted sample characteristics, foreign-born Asian adults $(N=1639)$

\begin{tabular}{|c|c|c|c|c|c|c|}
\hline & \multicolumn{2}{|c|}{$\begin{array}{l}\text { Assimilated } \\
(N=241)\end{array}$} & \multicolumn{2}{|c|}{$\begin{array}{l}\text { Integrated } \\
(N=718)\end{array}$} & \multicolumn{2}{|c|}{$\begin{array}{l}\text { Separated } \\
(N=680)\end{array}$} \\
\hline & Women & Men & Women & Men & Women & Men \\
\hline Poor-to-fair self-rated physical health, $\%$ & .10 & .14 & .09 & .07 & .36 & .25 \\
\hline \multicolumn{7}{|l|}{ Demographic characteristics } \\
\hline Age at interview, mean & $\begin{array}{l}34.29 \\
(12.99)\end{array}$ & $\begin{array}{l}36.64 \\
(14.70)\end{array}$ & $\begin{array}{l}40.14 \\
(13.34)\end{array}$ & $\begin{array}{l}40.81 \\
(13.24)\end{array}$ & $\begin{array}{l}46.95 \\
(13.04)\end{array}$ & $\begin{array}{l}47.20 \\
(14.99)\end{array}$ \\
\hline \multicolumn{7}{|l|}{ Marital status, $\%$} \\
\hline Married or cohabiting & .59 & .49 & .76 & .80 & .78 & .77 \\
\hline Formerly married & .10 & .03 & .09 & .03 & .14 & .06 \\
\hline Never married & .31 & .47 & .15 & .17 & .09 & .16 \\
\hline Family size, mean & $\begin{array}{l}2.85 \\
(1.53)\end{array}$ & $\begin{array}{l}2.61 \\
(1.45)\end{array}$ & $\begin{array}{l}2.86 \\
(1.57)\end{array}$ & $\begin{array}{l}2.85 \\
(1.58)\end{array}$ & $\begin{array}{l}3.18 \\
(1.63)\end{array}$ & $\begin{array}{l}3.07 \\
(1.63)\end{array}$ \\
\hline \multicolumn{7}{|l|}{ Ethnic identity, $\%$} \\
\hline Chinese & .27 & .30 & .20 & .23 & .45 & .41 \\
\hline Vietnamese & .08 & .11 & .05 & .09 & .34 & .31 \\
\hline Filipino & .26 & .25 & .28 & .23 & .08 & .09 \\
\hline Other Asian & .38 & .34 & .47 & .44 & .13 & .19 \\
\hline \multicolumn{7}{|l|}{ Socioeconomic status } \\
\hline \multicolumn{7}{|l|}{ Years of completed schooling, \% } \\
\hline $0-11$ years & .07 & .08 & .07 & .06 & .41 & .35 \\
\hline 12 years & .18 & .15 & .13 & .12 & .21 & .23 \\
\hline $13-15$ years & .35 & .25 & .26 & .17 & .18 & .18 \\
\hline 16 or more years & .40 & .52 & .54 & .65 & .19 & .24 \\
\hline Employed, \% & .69 & .79 & .71 & .85 & .63 & .79 \\
\hline Income-to-poverty index, mean & $\begin{array}{l}6.26 \\
(4.95)\end{array}$ & $\begin{array}{l}8.07 \\
(5.48)\end{array}$ & $\begin{array}{l}6.73 \\
(5.10)\end{array}$ & $\begin{array}{l}6.81 \\
(5.02)\end{array}$ & $\begin{array}{l}3.38 \\
(3.87)\end{array}$ & $\begin{array}{l}4.01 \\
(3.93)\end{array}$ \\
\hline \multicolumn{7}{|l|}{ Stress and support } \\
\hline Level of acculturative stress, mean & $\begin{array}{l}1.17 \\
(1.19)\end{array}$ & $\begin{array}{l}.93 \\
(1.12)\end{array}$ & $\begin{array}{l}1.53 \\
(1.53)\end{array}$ & $\begin{array}{l}1.63 \\
(1.56)\end{array}$ & $\begin{array}{l}2.27 \\
(1.83)\end{array}$ & $\begin{array}{l}2.39 \\
(1.79)\end{array}$ \\
\hline Level of family cohesion, mean & $\begin{array}{l}35.60 \\
(5.35)\end{array}$ & $\begin{array}{l}35.80 \\
(5.45)\end{array}$ & $\begin{array}{l}37.38 \\
(4.34)\end{array}$ & $\begin{array}{l}37.81 \\
(3.75)\end{array}$ & $\begin{array}{l}37.59 \\
(3.88)\end{array}$ & $\begin{array}{l}37.40 \\
(3.78)\end{array}$ \\
\hline Level of family cultural conflict, mean & $\begin{array}{l}7.20 \\
(2.16)\end{array}$ & $\begin{array}{l}6.87 \\
(1.94)\end{array}$ & $\begin{array}{l}6.68 \\
(1.79)\end{array}$ & $\begin{array}{l}6.29 \\
(1.62)\end{array}$ & $\begin{array}{l}6.11 \\
(1.72)\end{array}$ & $\begin{array}{l}6.27 \\
(1.75)\end{array}$ \\
\hline Frequency of talking to relatives, mean & $\begin{array}{l}3.40 \\
(1.21)\end{array}$ & $\begin{array}{l}3.02 \\
(1.21)\end{array}$ & $\begin{array}{l}3.40 \\
(1.20)\end{array}$ & $\begin{array}{l}3.07 \\
(1.15)\end{array}$ & $\begin{array}{l}2.88 \\
(1.33)\end{array}$ & $\begin{array}{l}2.76 \\
(1.27)\end{array}$ \\
\hline Feelings of opening up to relatives, mean & $\begin{array}{l}2.89 \\
(1.03)\end{array}$ & $\begin{array}{l}2.81 \\
(1.11)\end{array}$ & $\begin{array}{l}2.97 \\
(1.01)\end{array}$ & $\begin{array}{l}2.66 \\
(1.04)\end{array}$ & $\begin{array}{l}2.42 \\
(1.00)\end{array}$ & $\begin{array}{l}2.33 \\
(.97)\end{array}$ \\
\hline Feelings of reliance on relatives, mean & $\begin{array}{l}3.34 \\
(.91)\end{array}$ & $\begin{array}{l}3.09 \\
(1.03)\end{array}$ & $\begin{array}{l}3.04 \\
(1.06)\end{array}$ & $\begin{array}{l}2.89 \\
(1.06)\end{array}$ & $\begin{array}{l}2.43 \\
(1.06)\end{array}$ & $\begin{array}{l}2.35 \\
(1.05)\end{array}$ \\
\hline Frequent attendance at religious services, $\%$ & .33 & .28 & .49 & .44 & .35 & .35 \\
\hline Sample size & 112 & 129 & 371 & 347 & 385 & 295 \\
\hline
\end{tabular}

Standard deviations in parentheses 
Demographically, men and women in the separated group are the oldest (mean ages around 47) while both men and women in the assimilated group are the youngest (mean age about 37 and 34, respectively). Regardless of acculturation status, married or cohabiting respondents comprise the largest proportion of the sample, both among men and among women. However, rates of marriage/cohabitation are lowest among the assimilated, where we see that a substantial portion of adults are never married (31\% of women and $47 \%$ of men). Family size is largest among the separated regardless of gender. In terms of ethnic composition, Chinese and Vietnamese respondents comprise the majority among the separated, with $45 \%$ and $34 \%$ for women and $41 \%$ and $31 \%$ for men, respectively. Among the assimilated and integrated groups, 'other Asian' comprises the largest proportion, closely followed by Chinese among the assimilated (27\% for women and $30 \%$ for men) and by Filipino among the integrated (28\% for women and $23 \%$ among men, on par with Chinese for men).

Socioeconomically, Table 2 shows that assimilated and integrated Asian immigrants are better off than the separated. The separated report much lower levels of completed schooling and income, although their employment levels are more similar to the other groups. The integrated is the most highly educated group regardless of gender, with $54 \%$ of women and $65 \%$ of men reporting at least 16 years of education. The integrated also reports slightly higher employment rates than the assimilated. However, there is gender difference when looking at income, as assimilated men show the highest income-to-poverty ratio (8.07), while for women income-topoverty is highest among the integrated (6.73).

Turning to measures of stress and support, Table 2 shows that acculturative stress is greatest among the separated, regardless of gender (score of 2.27 for women and 2.39 for men), followed by the integrated (score of 1.53 for women and 1.63 for men) and the assimilated (score of 1.17 for women and .93 for men). The separated (men and women) also report less support from relatives, and they attend religious services less often than the integrated. Additionally, while levels of family cohesion are similar across acculturation groups, assimilated men and women report more family cultural conflict than the integrated or separated. However, the assimilated also report greater feelings of reliance on relatives.

\section{Logistic Regression Models Predicting Poor-to-Fair Self-rated Health}

Tables 3, 4, and 5 present odds ratios from multivariate logistic regression models predicting poor-to-fair self-rated physical health among Asian immigrants. Models for the pooled sample are included in Table 3, and we begin with our baseline Model 1 that regresses self-rated physical health on acculturation status and demographic characteristics. It shows that the separated group has 2.07 times greater odds of reporting poor-to-fair self-rated physical health than the assimilated group, controlling for demographic characteristics. It also shows that yearly increase in age is associated with $4 \%$ higher odds of reporting poor-to-fair self-rated physical health, and that Vietnamese and Filipino respondents have significantly lower odds $(30 \%$ 
Table 3 Odds ratios from logistic regression models predicting poor-to-fair SRH, pooled sample $(N=1639)$

\begin{tabular}{|c|c|c|c|c|}
\hline & Model 1 & Model 2 & Model 3 & Model 4 \\
\hline \multicolumn{5}{|c|}{ Acculturation status (ref: Assimilated) } \\
\hline Integrated & $\begin{array}{l}.56 \\
(.29-1.08)\end{array}$ & $\begin{array}{l}.55 \\
(.28-1.09)\end{array}$ & $\begin{array}{l}.57 \\
(.30-1.09)\end{array}$ & $\begin{array}{l}.53 \\
(.16-1.77)\end{array}$ \\
\hline Separated & $\begin{array}{l}2.07 * \\
(1.19-3.60)\end{array}$ & $\begin{array}{l}1.76^{*} \\
(1.02-3.04)\end{array}$ & $\begin{array}{l}1.78 * \\
(1.02-3.08)\end{array}$ & $\begin{array}{l}4.25^{*} \\
(1.29-13.97)\end{array}$ \\
\hline \multicolumn{5}{|l|}{ Demographic characteristics } \\
\hline Age at interview & $\begin{array}{l}1.04 * * * \\
(1.02-1.05)\end{array}$ & $\begin{array}{l}1.03 * * * \\
(1.02-1.04)\end{array}$ & $\begin{array}{l}1.03 * * * \\
(1.02-1.05)\end{array}$ & $\begin{array}{l}1.04 * * * \\
(1.02-1.07)\end{array}$ \\
\hline Women & $\begin{array}{l}1.31 \\
(.87-1.98)\end{array}$ & $\begin{array}{l}1.15 \\
(.75-1.76)\end{array}$ & $\begin{array}{l}1.23 \\
(.79-1.91)\end{array}$ & $\begin{array}{l}1.25 \\
(.81-1.93)\end{array}$ \\
\hline \multicolumn{5}{|c|}{ Marital status (ref: Married or cohabiting) } \\
\hline Formerly married & $\begin{array}{l}1.03 \\
(.55-1.92)\end{array}$ & $\begin{array}{l}.74 \\
(.39-1.40)\end{array}$ & $\begin{array}{l}.68 \\
(.38-1.20)\end{array}$ & $\begin{array}{l}.68 \\
(.38-1.21)\end{array}$ \\
\hline Never married & $\begin{array}{l}1.04 \\
(.59-1.85)\end{array}$ & $\begin{array}{l}.74 \\
(.40-1.35)\end{array}$ & $\begin{array}{l}.65 \\
(.36-1.18)\end{array}$ & $\begin{array}{l}.69 \\
(.40-1.19)\end{array}$ \\
\hline Family size & $\begin{array}{l}1.00 \\
(.88-1.14)\end{array}$ & $\begin{array}{l}.95 \\
(.82-1.09)\end{array}$ & $\begin{array}{l}.95 \\
(.82-1.10)\end{array}$ & $\begin{array}{l}.95 \\
(.82-1.10)\end{array}$ \\
\hline \multicolumn{5}{|l|}{ Ethnic identity (ref: Chinese) } \\
\hline Vietnamese & $\begin{array}{l}.70^{*} \\
(.51-.95)\end{array}$ & $\begin{array}{l}.62 * * \\
(.44-.86)\end{array}$ & $\begin{array}{l}.66^{* *} \\
(.48-.90)\end{array}$ & $\begin{array}{l}.64 * * \\
(.47-.88)\end{array}$ \\
\hline Filipino & $\begin{array}{l}.57 * \\
(.36-.90)\end{array}$ & $\begin{array}{l}.59 * \\
(.38-.92)\end{array}$ & $\begin{array}{l}.66 \\
(.39-1.09)\end{array}$ & $\begin{array}{l}.63 \\
(.37-1.07)\end{array}$ \\
\hline Other Asian & $\begin{array}{l}.64 \\
(.39-1.05)\end{array}$ & $\begin{array}{l}.61 \\
(.35-1.07)\end{array}$ & $\begin{array}{l}.64 \\
(.36-1.13)\end{array}$ & $\begin{array}{l}.62 \\
(.36-1.10)\end{array}$ \\
\hline \multicolumn{5}{|l|}{ Socioeconomic status } \\
\hline \multicolumn{5}{|c|}{ Years of completed schooling (ref: $0-11$ years) } \\
\hline 12 years & & $\begin{array}{l}1.05 \\
(.71-1.56)\end{array}$ & $\begin{array}{l}1.06 \\
(.70-1.61)\end{array}$ & $\begin{array}{l}1.00 \\
(.68-1.48)\end{array}$ \\
\hline $13-15$ years & & $\begin{array}{l}1.07 \\
(.72-1.57)\end{array}$ & $\begin{array}{l}1.08 \\
(.75-1.53)\end{array}$ & $\begin{array}{l}1.03 \\
(.74-1.44)\end{array}$ \\
\hline 16 or more years & & $\begin{array}{l}.92 \\
(.58-1.45)\end{array}$ & $\begin{array}{l}.92 \\
(.61-1.38)\end{array}$ & $\begin{array}{l}.88 \\
(.60-1.29)\end{array}$ \\
\hline Employed & & $\begin{array}{l}.52 * * \\
(.32-.84)\end{array}$ & $\begin{array}{l}.52 \\
(.31-.85)\end{array}$ & $\begin{array}{l}.50 * * \\
(.31-.82)\end{array}$ \\
\hline Income-to-poverty index & & $\begin{array}{l}.94 * \\
(.89-.99)\end{array}$ & $\begin{array}{l}.94 * \\
(.89-.99)\end{array}$ & $\begin{array}{l}.94 * \\
(.88-.99)\end{array}$ \\
\hline \multicolumn{5}{|l|}{ Stress and support } \\
\hline Level of acculturative stress & & & $\begin{array}{l}1.03 \\
(.94-1.14)\end{array}$ & $\begin{array}{l}1.04 \\
(.95-1.14)\end{array}$ \\
\hline Level of family cohesion & & & $\begin{array}{l}.98 \\
(.94-1.02)\end{array}$ & $\begin{array}{l}.98 \\
(.94-1.02)\end{array}$ \\
\hline Level of family cultural conflict & & & $\begin{array}{l}1.10 * \\
(1.01-1.20)\end{array}$ & $\begin{array}{l}1.09 \\
(.99-1.19)\end{array}$ \\
\hline Frequency of talking to relatives & & & $\begin{array}{l}.85 \\
(.72-1.02)\end{array}$ & $\begin{array}{l}.85^{*} \\
(.72-1.00)\end{array}$ \\
\hline
\end{tabular}


Table 3 (continued)

\begin{tabular}{|c|c|c|c|c|}
\hline & Model 1 & Model 2 & Model 3 & Model 4 \\
\hline Feelings of opening up to relatives & & & $\begin{array}{l}.96 \\
(.72-1.27)\end{array}$ & $\begin{array}{l}.97 \\
(.75-1.27)\end{array}$ \\
\hline Feelings of reliance on relatives & & & $\begin{array}{l}1.10 \\
(.87-1.41)\end{array}$ & $\begin{array}{l}1.09 \\
(.87-1.37)\end{array}$ \\
\hline Frequent attendance at religious services & & & $\begin{array}{l}.86 \\
(.50-1.49)\end{array}$ & $\begin{array}{l}.86 \\
(.50-1.49)\end{array}$ \\
\hline \multicolumn{5}{|l|}{ Age at interview $\times$ acculturation status } \\
\hline Integrated & & & & $\begin{array}{l}1.00 \\
(.97-1.04)\end{array}$ \\
\hline Separated & & & & $\begin{array}{l}.98 \\
(.96-1.01)\end{array}$ \\
\hline
\end{tabular}

95\% confidence intervals in parentheses

$* p \leq .05, * * p \leq .01, * * * p \leq .001$

and $43 \%$, respectively) of reporting poor-to-fair self-rated physical health than Chinese respondents.

In Models 2 and 3, we additionally adjust for measures that may confound the association between acculturation status and poor-to-fair self-rated physical health. In Model 2, we find that including socioeconomic status results in a slight reduction in the odds of reporting poor-to-fair self-rated physical health for the separated group (from 2.07 to 1.76). We also find that being employed is associated with $48 \%$ lower odds of reporting poor-to-fair self-rated physical health, and that a unit increase in income-to-poverty index is associated with $6 \%$ lower odds of reporting poor-to-fair self-rated physical health. When we add stress and support measures in Model 3, the odds ratio for the separated group barely shifts (OR 1.78). Importantly, Model 3 also shows that increasing family cultural conflict is associated with significantly higher odds of reporting poor-to-fair self-rated physical health.

Last, in Model 4, we test the interaction between age*acculturation status, indicating that in the pooled sample, we do not find evidence that age moderates the relationship between acculturation and poor-to-fair SRH among Asian immigrants. We do find that frequency of talking to relatives is associated with $15 \%$ lower odds of reporting poor-to-fair self-rated physical health.

\section{Differences by Gender}

Tables 4 and 5 present odds ratios from the same multivariate logistic regression models predicting poor-to-fair self-rated physical health, stratified by gender. In Table 4, and similar to findings from our pooled models, there is a significantly heightened risk of poor-to-fair self-rated physical health for separated compared to assimilated Asian immigrant women. Adjusting for controls somewhat reduces this association, but the odds are still 2.62 times greater in Model 2. Looking across Models 1-3, we again find that age and ethnic identity are significant factors associated with poor-to-fair self-rated physical health, but among women only, the 
Table 4 Odds ratios from logistic regression models predicting poor-to-fair SRH, women $(N=868)$

\begin{tabular}{|c|c|c|c|c|}
\hline & Model 1 & Model 2 & Model 3 & Model 4 \\
\hline \multicolumn{5}{|c|}{ Acculturation status (ref: Assimilated) } \\
\hline Integrated & $\begin{array}{l}.73 \\
(.26-2.04)\end{array}$ & $\begin{array}{l}.84 \\
(.29-2.45)\end{array}$ & $\begin{array}{l}.80 \\
(.27-2.32)\end{array}$ & $\begin{array}{l}.04 * * \\
(.01-.37)\end{array}$ \\
\hline Separated & $\begin{array}{l}2.93 * * \\
(1.33-6.47)\end{array}$ & $\begin{array}{l}2.62 * \\
(1.14-6.02)\end{array}$ & $\begin{array}{l}2.32 \\
(.98-5.52)\end{array}$ & $\begin{array}{l}.35 \\
(.06-1.92)\end{array}$ \\
\hline \multicolumn{5}{|c|}{ Demographic characteristics } \\
\hline Age at interview & $\begin{array}{l}1.04 * * \\
(1.01-1.06)\end{array}$ & $\begin{array}{l}1.03 * \\
(1.00-1.06)\end{array}$ & $\begin{array}{l}1.03 * * \\
(1.01-1.06)\end{array}$ & $\begin{array}{l}.98 \\
(.95-1.02)\end{array}$ \\
\hline \multicolumn{5}{|c|}{ Marital status (ref: Married or cohabiting) } \\
\hline Formerly married & $\begin{array}{l}.99 \\
(.46-2.16)\end{array}$ & $\begin{array}{l}.68 \\
(.34-1.38)\end{array}$ & $\begin{array}{l}.65 \\
(.32-1.30)\end{array}$ & $\begin{array}{l}.67 \\
(.35-1.26)\end{array}$ \\
\hline Never married & $\begin{array}{l}.75 \\
(.28-2.02)\end{array}$ & $\begin{array}{l}.61 \\
(.25-1.48)\end{array}$ & $\begin{array}{l}.52 \\
(.19-1.38)\end{array}$ & $\begin{array}{l}.48 \\
(.18-1.29)\end{array}$ \\
\hline Family size & $\begin{array}{l}1.01 \\
(.87-1.18)\end{array}$ & $\begin{array}{l}.94 \\
(.79-1.12)\end{array}$ & $\begin{array}{l}.95 \\
(.80-1.13)\end{array}$ & $\begin{array}{l}.95 \\
(.79-1.13)\end{array}$ \\
\hline \multicolumn{5}{|c|}{ Ethnic identity (ref: Chinese) } \\
\hline Vietnamese & $\begin{array}{l}.58 \\
(.33-1.01)\end{array}$ & $\begin{array}{l}.46^{*} \\
(.25-.87)\end{array}$ & $\begin{array}{l}.49 \\
(.24-1.01)\end{array}$ & $\begin{array}{l}.48^{*} \\
(.24-.98)\end{array}$ \\
\hline Filipino & $\begin{array}{l}.51 \\
(.26-1.02)\end{array}$ & $\begin{array}{l}.52 \\
(.26-1.05)\end{array}$ & $\begin{array}{l}.64 \\
(.27-1.56)\end{array}$ & $\begin{array}{l}.59 \\
(.25-1.44)\end{array}$ \\
\hline Other Asian & $\begin{array}{l}.65 \\
(.34-1.25)\end{array}$ & $\begin{array}{l}.64 \\
(.31-1.31)\end{array}$ & $\begin{array}{l}.73 \\
(.32-1.63)\end{array}$ & $\begin{array}{l}.69 \\
(.33-1.44)\end{array}$ \\
\hline
\end{tabular}

Socioeconomic status

Years of completed schooling (ref: 0-11 years)

\begin{tabular}{|c|c|c|c|}
\hline 12 years & $\begin{array}{l}.92 \\
(.45-1.87)\end{array}$ & $\begin{array}{l}.98 \\
(.49-1.97)\end{array}$ & $\begin{array}{l}.92 \\
(.48-1.79)\end{array}$ \\
\hline $13-15$ years & $\begin{array}{l}.92 \\
(.56-1.53)\end{array}$ & $\begin{array}{l}1.01 \\
(.56-1.81)\end{array}$ & $\begin{array}{l}1.00 \\
(.55-1.84)\end{array}$ \\
\hline 16 or more years & $\begin{array}{l}.49 * \\
(.26-.91)\end{array}$ & $\begin{array}{l}.53 \\
(.28-1.00)\end{array}$ & $\begin{array}{l}.53 \\
(.27-1.01)\end{array}$ \\
\hline Employed & $\begin{array}{l}.49 * \\
(.28-.88)\end{array}$ & $\begin{array}{l}.47 * \\
(.26-.86)\end{array}$ & $\begin{array}{l}.47 * \\
(.26-.84)\end{array}$ \\
\hline Income-to-poverty index & $\begin{array}{l}.95 \\
(.87-1.03)\end{array}$ & $\begin{array}{l}.94 \\
(.86-1.03)\end{array}$ & $\begin{array}{l}.94 \\
(.87-1.02)\end{array}$ \\
\hline \multicolumn{4}{|l|}{ Stress and support } \\
\hline Level of acculturative stress & & $\begin{array}{l}1.13 \\
(.99-1.29)\end{array}$ & $\begin{array}{l}1.15 \\
(1.00-1.31)\end{array}$ \\
\hline Level of family cohesion & & $\begin{array}{l}.97 \\
(.90-1.05)\end{array}$ & $\begin{array}{l}.97 \\
(.89-1.05)\end{array}$ \\
\hline Level of family cultural conflict & & $\begin{array}{l}1.04 \\
(.91-1.20)\end{array}$ & $\begin{array}{l}1.05 \\
(.91-1.20)\end{array}$ \\
\hline Frequency of talking to relatives & & $\begin{array}{l}.83 \\
(.66-1.05)\end{array}$ & $\begin{array}{l}.83 \\
(.66-1.04)\end{array}$ \\
\hline Feelings of opening up to relatives & & $\begin{array}{l}.86 \\
(.56-1.30)\end{array}$ & $\begin{array}{l}.88 \\
(.61-1.27)\end{array}$ \\
\hline Feelings of reliance on relatives & & $\begin{array}{l}1.16 \\
(.82-1.62)\end{array}$ & $\begin{array}{l}1.14 \\
(.83-1.56)\end{array}$ \\
\hline
\end{tabular}


Table 4 (continued)

\begin{tabular}{|c|c|c|c|c|}
\hline & Model 1 & Model 2 & Model 3 & Model 4 \\
\hline Frequent attendance at religious services & & & $\begin{array}{l}.75 \\
(.23-2.48)\end{array}$ & $\begin{array}{l}.70 \\
(.21-2.38)\end{array}$ \\
\hline \multicolumn{5}{|l|}{ Age at interview $\times$ acculturation status } \\
\hline Integrated & & & & $\begin{array}{l}1.08 * * \\
(1.02-1.14)\end{array}$ \\
\hline Separated & & & & $\begin{array}{l}1.05^{*} \\
(1.01-1.10)\end{array}$ \\
\hline
\end{tabular}

95\% confidence intervals in parentheses

$* p \leq .05, * * p \leq .01, * * * p \leq .001$

Vietnamese have significantly lower odds of poor-to-fair self-rated physical health compared to the Chinese. Additionally, among Asian immigrant women, we also find that those with at least 16 years of education experience about half the odds of poor-to-fair self-rated physical health when compared to those with $<12$ years of completed schooling. For women, being employed is consistently associated with approximately 53\% lower odds of reporting poor-to-fair self-rated physical health.

In Model 4, we find that interaction between age and acculturation status is significant. For ease of interpretation, we graph this interaction using predicted probabilities in Fig. 1. It shows that among Asian immigrant women, the predicted probability of reporting poor-to-fair self-rated physical health declines slightly with age for those in the assimilated group. However, for other two groups, the predicted probability of reporting poor-to-fair self-rated physical health increases with age, with those in the separated group experiencing a consistently higher probability of poor-to-fair self-rated physical health than those in the integrated group.

In Table 5, our findings for Asian immigrant men differ from those just discussed for women. Looking at Models 1 through 3, we find the odds ratio for the separated group, while elevated, is not significantly different from the assimilated. However, after adjusting for income-to-poverty index in Model 2, the contrast between the integrated and the assimilated groups emerges as significant (with a $60 \%$ lower odds of reporting poor-to-fair self-rated physical health among the integrated). Once we adjust for family cultural conflict in Model 3, however, this contrast loses significance. In terms of control measures, Table 5 also shows that increase in income is associated with lower odds, and family cultural conflict with higher odds, of poorto-fair SRH.

In Model 4, we find that interaction between age and acculturation status is significant among Asian immigrant men (see Fig. 2), but the relationships shown differ from those discussed for women. We see much shallower increases in the predicted probability of poor-to-fair self-rated physical health with age among the separated and the integrated groups. However, the more notable difference is found among the assimilated group. While among women, being in the assimilated group was associated with a slight decline in the predicted probability of poor-to-fair self-rated physical health with age, among men, it is the opposite. We find that among assimilated 
Table 5 Odds ratios from logistic regression models predicting poor-to-fair SRH, men $(N=771)$

\begin{tabular}{|c|c|c|c|c|}
\hline & Model 1 & Model 2 & Model 3 & Model 4 \\
\hline \multicolumn{5}{|l|}{ Acculturation status (ref: Assimilated) } \\
\hline Integrated & $\begin{array}{l}.47 \\
(.21-1.05)\end{array}$ & $\begin{array}{l}.40^{*} \\
(.19-.87)\end{array}$ & $\begin{array}{l}.49 \\
(.23-1.04)\end{array}$ & $\begin{array}{l}2.78 \\
(.40-19.18)\end{array}$ \\
\hline Separated & $\begin{array}{l}1.56 \\
(.81-3.00)\end{array}$ & $\begin{array}{l}1.46 \\
(.68-3.14)\end{array}$ & $\begin{array}{l}1.68 \\
(.79-3.58)\end{array}$ & $\begin{array}{l}23.71 * * * \\
(4.17-134.70)\end{array}$ \\
\hline \multicolumn{5}{|l|}{ Demographic characteristics } \\
\hline Age at interview & $\begin{array}{l}1.04 * * * \\
(1.02-1.06)\end{array}$ & $\begin{array}{l}1.03 * * \\
(1.01-1.05)\end{array}$ & $\begin{array}{l}1.03 * * \\
(1.01-1.05)\end{array}$ & $\begin{array}{l}1.07 * * * \\
(1.05-1.10)\end{array}$ \\
\hline \multicolumn{5}{|c|}{ Marital status (ref: Married or cohabiting) } \\
\hline Formerly married & $\begin{array}{l}1.10 \\
(.30-4.10)\end{array}$ & $\begin{array}{l}.92 \\
(.24-3.50)\end{array}$ & $\begin{array}{l}.72 \\
(.22-2.40)\end{array}$ & $\begin{array}{l}.74 \\
(.25-2.22)\end{array}$ \\
\hline Never married & $\begin{array}{l}1.40 \\
(.80-2.43)\end{array}$ & $\begin{array}{l}.88 \\
(.44-1.79)\end{array}$ & $\begin{array}{l}.71 \\
(.34-1.48)\end{array}$ & $\begin{array}{l}.76 \\
(.37-1.56)\end{array}$ \\
\hline Family size & $\begin{array}{l}.98 \\
(.84-1.16)\end{array}$ & $\begin{array}{l}.93 \\
(.80-1.09)\end{array}$ & $\begin{array}{l}.93 \\
(.80-1.09)\end{array}$ & $\begin{array}{l}.93 \\
(.79-1.09)\end{array}$ \\
\hline \multicolumn{5}{|l|}{ Ethnic identity (ref: Chinese) } \\
\hline Vietnamese & $\begin{array}{l}.87 \\
(.47-1.60)\end{array}$ & $\begin{array}{l}.84 \\
(.44-1.61)\end{array}$ & $\begin{array}{l}.86 \\
(.45-1.66)\end{array}$ & $\begin{array}{l}.82 \\
(.43-1.56)\end{array}$ \\
\hline Filipino & $\begin{array}{l}.68 \\
(.30-1.53)\end{array}$ & $\begin{array}{l}.77 \\
(.33-1.84)\end{array}$ & $\begin{array}{l}.69 \\
(.27-1.77)\end{array}$ & $\begin{array}{l}.59 \\
(.22-1.59)\end{array}$ \\
\hline Other Asian & $\begin{array}{l}.65 \\
(.39-1.07)\end{array}$ & $\begin{array}{l}.59 \\
(.33-1.07)\end{array}$ & $\begin{array}{l}.52 * \\
(.28-.95)\end{array}$ & $\begin{array}{l}.43 * * \\
(.24-.77)\end{array}$ \\
\hline \multicolumn{5}{|l|}{ Socioeconomic status } \\
\hline \multicolumn{5}{|c|}{ Years of completed schooling (ref: $0-11$ years) } \\
\hline 12 years & & $\begin{array}{l}1.26 \\
(.65-2.45)\end{array}$ & $\begin{array}{l}1.16 \\
(.63-2.14)\end{array}$ & $\begin{array}{l}1.04 \\
(.58-1.85)\end{array}$ \\
\hline $13-15$ years & & $\begin{array}{l}1.27 \\
(.59-2.73)\end{array}$ & $\begin{array}{l}1.12 \\
(.58-2.54)\end{array}$ & $\begin{array}{l}1.15 \\
(.55-2.41)\end{array}$ \\
\hline 16 or more years & & $\begin{array}{l}1.96 \\
(.92-4.16)\end{array}$ & $\begin{array}{l}1.69 \\
(.79-3.59)\end{array}$ & $\begin{array}{l}1.46 \\
(.71-2.99)\end{array}$ \\
\hline Employed & & $\begin{array}{l}.53 \\
(.21-1.33)\end{array}$ & $\begin{array}{l}.53 \\
(.21-1.32)\end{array}$ & $\begin{array}{l}.48 \\
(.22-1.08)\end{array}$ \\
\hline Income-to-poverty index & & $\begin{array}{l}.93^{*} \\
(.86-1.00)\end{array}$ & $\begin{array}{l}.93 \\
(.86-1.00)\end{array}$ & $\begin{array}{l}.92 * \\
(.85-1.00)\end{array}$ \\
\hline \multicolumn{5}{|l|}{ Stress and support } \\
\hline Level of acculturative stress & & & $\begin{array}{l}.94 \\
(.78-1.12)\end{array}$ & $\begin{array}{l}.95 \\
(.79-1.14)\end{array}$ \\
\hline Level of family cohesion & & & $\begin{array}{l}.99 \\
(.93-1.05)\end{array}$ & $\begin{array}{l}.99 \\
(.93-1.05)\end{array}$ \\
\hline Level of family cultural conflict & & & $\begin{array}{l}1.19 * * \\
(1.05-1.34)\end{array}$ & $\begin{array}{l}1.17 * \\
(1.03-1.33)\end{array}$ \\
\hline Frequency of talking to relatives & & & $\begin{array}{l}.91 \\
(.74-1.13)\end{array}$ & $\begin{array}{l}.86 \\
(.69-1.07)\end{array}$ \\
\hline Feelings of opening up to relatives & & & $\begin{array}{l}1.12 \\
(.89-1.43)\end{array}$ & $\begin{array}{l}1.13 \\
(.88-1.47)\end{array}$ \\
\hline Feelings of reliance on relatives & & & $\begin{array}{l}1.00 \\
(.76-1.31)\end{array}$ & $\begin{array}{l}1.03 \\
(.77-1.36)\end{array}$ \\
\hline
\end{tabular}


Table 5 (continued)

\begin{tabular}{|c|c|c|c|c|}
\hline & Model 1 & Model 2 & Model 3 & Model 4 \\
\hline Frequent attendance at religious services & & & $\begin{array}{l}1.02 \\
(.50-2.09)\end{array}$ & $\begin{array}{l}1.12 \\
(.58-2.16)\end{array}$ \\
\hline \multicolumn{5}{|l|}{ Age at interview $\times$ acculturation status } \\
\hline Integrated & & & & $\begin{array}{l}.96 \\
(.91-1.01)\end{array}$ \\
\hline Separated & & & & $\begin{array}{l}.94 * * \\
(.91-.98)\end{array}$ \\
\hline
\end{tabular}

95\% confidence intervals in parentheses

$* p \leq .05, * * p \leq .01, * * * p \leq .001$

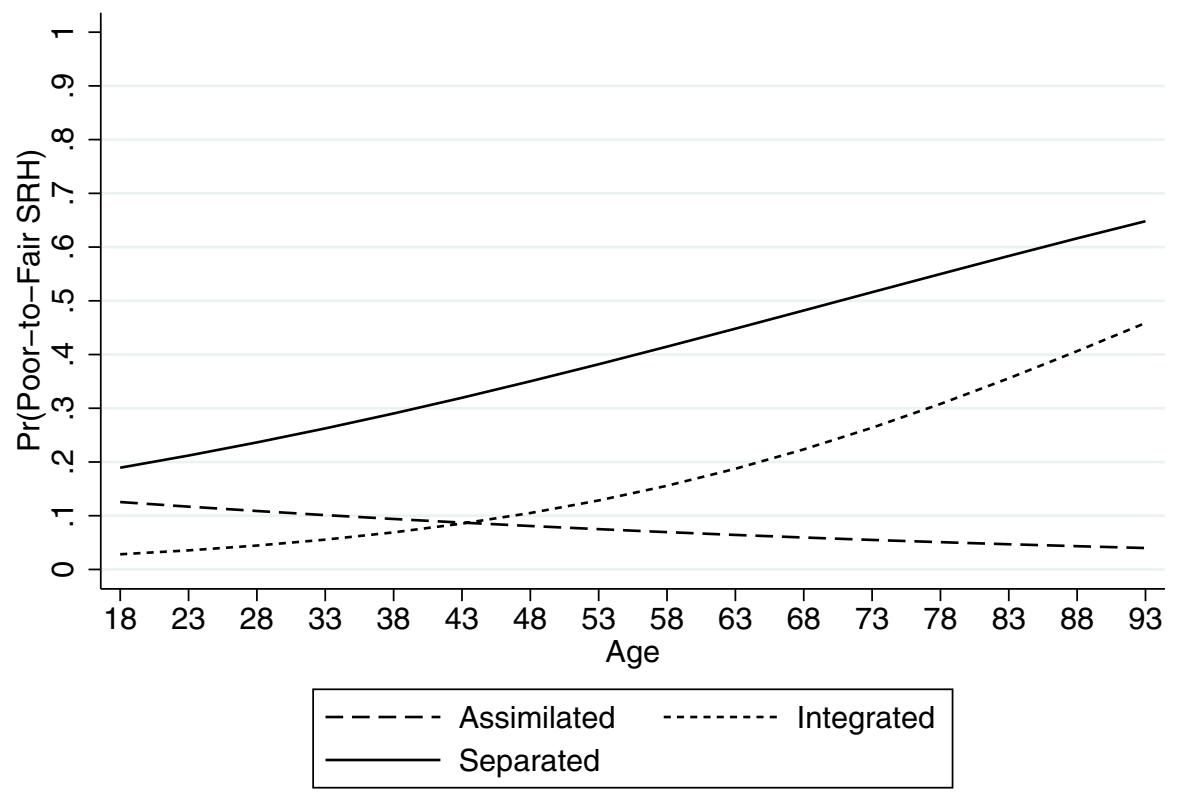

Note: Based on Model 4, Table 4.

Fig. 1 Predicted probabilities of poor-to-fair SRH for Asian immigrant women

Asian immigrant men, there is a strong increase in the predicted probability of poorto-fair self-rated physical health with age.

\section{Conclusion}

The Asian population in the U.S. is projected to grow rapidly, and by 2060 , the population is estimated to at least double for Asian-alone or in combination with other races (Colby and Ortman 2014). This means that by 2060, the Asian-alone 


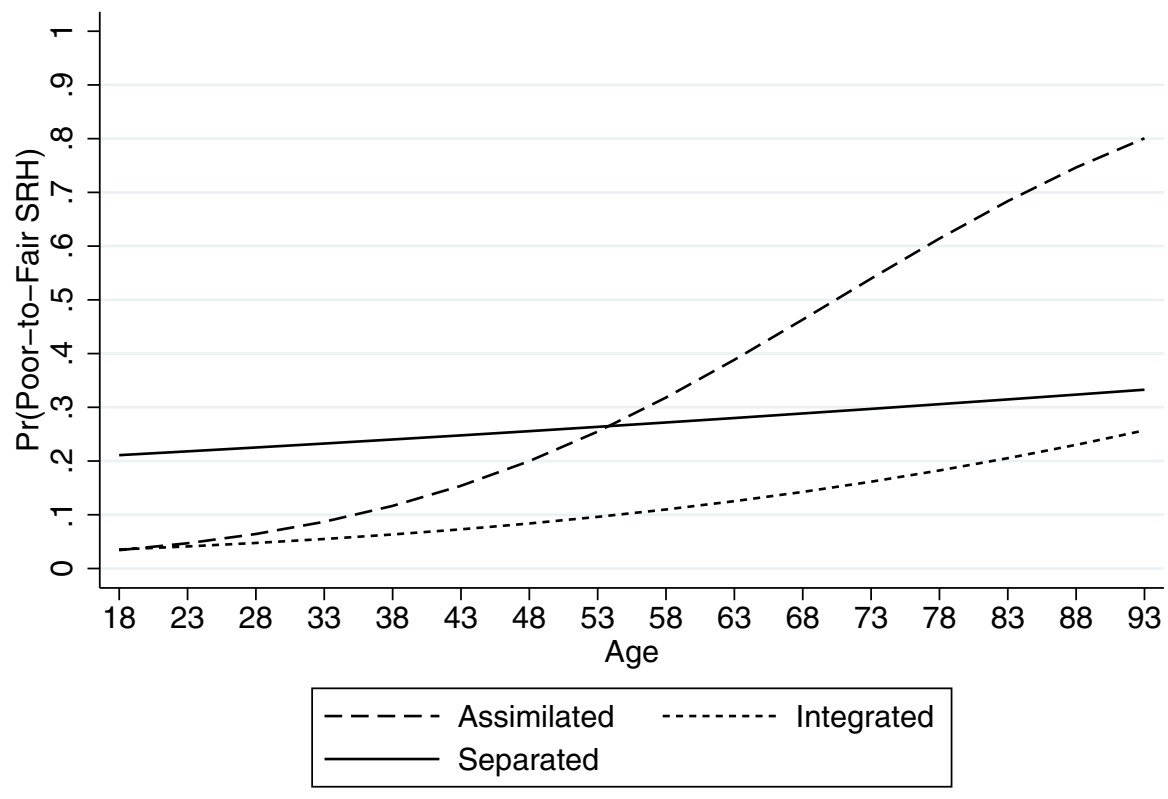

Note: Based on Model 4, Table 5.

Fig. 2 Predicted probabilities of poor-to-fair SRH for Asian immigrant men

population will account for about $9.3 \%$ of the total U.S. population. At the same time, Asians are expected to be the second-largest foreign-born population after Latin Americans (Colby and Ortman 2014). Such projections signal that examining how this rapidly increasing group, which contains a considerable proportion of immigrants, adapts to U.S. society and how such process affects their health will become increasingly important to public health and medical professionals.

While the relationship between acculturation and health among immigrants is well studied, most prior work examines single measure proxies for acculturation status (e.g., duration of residence in the United States), often with a focus of assessing acculturation relative only to U.S. culture. Less work has utilized a multidimensional approach to acculturation that more accurately reflects the processes of cultural adaptation among immigrants. Such an approach is needed among studies of Asian immigrants, who tend to remain strongly attached to their ethnic cultures, through family or co-ethnic communities (Min 1992; Wong et al. 2005). As such, we organized our analysis to compare self-rated health across three groups of Asian immigrant adults: the assimilated (those who exhibit strongest adherence to U.S. culture), the integrated (those who demonstrate considerable involvement in both U.S. and Asian ethnic cultures), and the separated (those who are almost exclusively attached to Asian ethnic cultures).

We used latent class analysis to identify groups of immigrants with potentially varying acculturation status. Reflecting our theoretical framework in which acculturation is viewed as a multidimensional process (Berry 1970, 2003), we constructed acculturation as composed of two separate dimensions: one of exposure to U.S. 
culture and another of affiliation with Asian ethnic cultures. As constituting each dimension, we utilized duration of U.S. residence and English proficiency as measures of exposure to U.S. culture and level of ethnic attachment and native-language proficiency as measures of affiliation with Asian ethnic cultures. Our measure of ethnic attachment, as a composite average score across three items, allowed us to gauge Asian immigrants' psychological affinity, such as feelings of closeness in ideas, with their ethnic communities. Furthermore, we use English as well as nativelanguage proficiency - also as average scores across speaking, reading, and writing abilities-since it is a more consistent predictor of self-rated health compared to other operationalizations of language use (Gee et al. 2010). This led us to effectively distinguish between classes of acculturation status wherein they become distinct with proficiency in one, the other, or both. Together with duration of U.S. residence as a classic component of exposure to U.S. culture, our use of latent class analysis that simultaneously considered these measures produced three classes of acculturation status with the best model fit: the assimilated, separated, and integrated groups. With these discrete groups of acculturating immigrants, we were able to examine their reports of self-rated health with age as well as by gender.

Findings revealed that among the pooled sample of Asian immigrants, the separated have significantly higher odds of reporting poor-to-fair self-rated physical health compared to the assimilated. Although age did not moderate the relationship between acculturation and SRH, it was consistently and positively associated with poor-to-fair self-rated physical health. This is in line with previous research showing that a considerable proportion of elderly Asian immigrants live in linguistic isolation (Wong et al. 2007) and tend to seek primary care within the family (Shin 2002), as well as other work showing that family can operate as a significant source of distress among Asian Americans (Zhang et al. 2012) and may prevent them from accessing and utilizing health services (Kang et al. 2010; Shin 2002).

Gender-stratified models further revealed considerably different patterns in the relationship between acculturation and self-rated physical health. We found that among Asian immigrant women, the separated have significantly greater odds of reporting poor-to-fair self-rated physical health than the assimilated. Our models also demonstrated that age was a significant moderator in this relationship, where the probability of reporting poor-to-fair self-rated physical health increased with age for the separated as well as for the integrated. The probability of reporting poor-tofair self-rated physical health among the assimilated actually declined with age. This pattern may be a reflection of increasing demand and conflict within the family as Asian women age that is negatively associated with health, particularly for those with greater ethnic identification (Leu et al. 2011). For Asian women who maintain strong ties almost exclusively to their co-ethnics, including the family, domestic responsibilities that pertain to care work may function as a significant barrier to caring for themselves, resulting in a negative influence on their perceived health status. Conversely, assimilated Asian women may experience more emancipation that comes with stronger attachment to U.S. culture, one that is assumed to be relatively more egalitarian than that of their origin countries.

We found that among Asian immigrant men, the patterns were reverse with the assimilated experiencing the steepest increase in the probability of reporting 
poor-to-fair self-rated physical health with age. The separated and the integrated experienced relatively shallower increases in the probability of reporting poor-to-fair self-rated physical health with age. Though not shown here, the assimilated had the greatest proportion of those who are overweight/obese, and men report the highest score of discrimination in our sample. Previous studies have demonstrated a shift toward overweight/obesity with increasing years in the U.S. (Choi 2012; Lauderdale and Rathouz 2000; Singh et al. 2011), as well as documenting associations between everyday discrimination and chronic health conditions (Gee et al. 2007) and various mental health outcomes (Hahm et al. 2010; Zhang and Hong 2013). Our findings for assimilated Asian men may partially reflect such factors that are negatively associated with overall health status.

While we have identified variable associations between acculturation and selfrated physical health among Asian immigrants, our study has its limitations. First, while we did identify ethnic differences among the Chinese, the Vietnamese, and the Filipinos, our sample of 'Other Asians' was not large enough to facilitate examination of more ethnic variation. Asian Americans are a group of considerable heterogeneity, composed of people who come from approximately 19 regions across East Asia, Southeast Asia, and the Indian subcontinent with varying socioeconomic statuses and proportions foreign born (Pew Research Center 2019). Furthermore, the existence of remote acculturation (Ferguson and Bornstein 2012) or pre-acculturation (Gee et al. 2019), fueled by globalization, signals that the extent to which migrating Asians are already exposed to U.S. culture may vary across these regions. Thus, a larger sample is needed for future research in order to better understand how acculturation is associated with self-rated health among such various Asian ethnic groups. Our analysis also drew on data from the NLAAS, collected in 2002-2003. While the dataset is not new, no other existing study includes information on detailed facets of psychological attachment (e.g., feelings of closeness in ideas to one's racial/ethnic descent) as an integral component of acculturation along with more popular proxies such as duration of residence in the U.S. More recent data that include ethnically diverse samples of U.S. and foreign-born Asian adults along with detailed information on acculturation and health status are needed. Third, our data are cross sectional, indicating that we have identified patterns of associations rather than causal processes between acculturation and health status. Considering that our models identify age as a significant moderator in the relationship between acculturation and self-rated health regardless of gender, a longitudinal study design that tracks shifts in self-rated health along with age among different acculturation groups is needed. Future research with such a design will yield a more elaborate understanding of how diverse processes of cultural adaptation, throughout their lives, affect health among the Asian immigrant population.

Despite such limitations, our study has its strengths in that it broadens the scope of research on acculturation and health among immigrants by conceptualizing acculturation as a dynamic process involving not only U.S. culture but also heritage ethnic cultures. Previous research in line with such a perspective has demonstrated that among Mexican immigrants, those with the lowest level of U.S. acculturation are the healthiest, especially for men (Gorman et al. 2010). Our study partly supports such a finding in that among Asian immigrant men, the assimilated reported the steepest 
decline in self-rated health with age than other groups. However, we found that among Asian immigrant women, the assimilated are the healthiest, with the separated reporting the poorest health status. Thus, our findings indicate that the ways in which the processes of cultural adaptation have implications for health status differ considerably across race/ethnicity as well as within race/ethnicity by gender. Further confirmation of the factors that lead to such outcome, particularly with a longitudinal framework, will provide more fine-grained understandings of what is distinct about Asian acculturation in the U.S. and its impacts on their health. In terms of mental versus physical health, Bulut and Gayman (2016) have found, using classes of immigrants among Latin Americans and Asians, that bicultural immigrants report the best self-rated mental health, and that the separated and recently arrived immigrants report the worst. Our findings are supportive in that the separated reported the worst self-rated physical health among the pooled sample and among women, and that the integrated reported the best among men. Considering the mechanisms involved in self-ratings of health (Jylhä 2009), research identifying what aspects of immigrant life among the separated and the integrated lead to such similar outcomes in both mental and physical health is needed.

\section{Funding None.}

Data Availability Data are available from the Inter-university Consortium for Political and Social Research (ICPSR).

Code Availability Stata 16.0 .

\section{Compliance with Ethical Standards}

Conflict of interest The authors declare that they have no conflict of interest.

Open Access This article is licensed under a Creative Commons Attribution 4.0 International License, which permits use, sharing, adaptation, distribution and reproduction in any medium or format, as long as you give appropriate credit to the original author(s) and the source, provide a link to the Creative Commons licence, and indicate if changes were made. The images or other third party material in this article are included in the article's Creative Commons licence, unless indicated otherwise in a credit line to the material. If material is not included in the article's Creative Commons licence and your intended use is not permitted by statutory regulation or exceeds the permitted use, you will need to obtain permission directly from the copyright holder. To view a copy of this licence, visit http://creativecommons.org/licen ses/by/4.0/.

\section{References}

Abraído-Lanza, A. F., Armbrister, A. N., Flórez, K. R., \& Aguirre, A. N. (2006). Toward a theorydriven model of acculturation in public health research. American Journal of Public Health, 96(8), 1342-1346.

Acevedo-Garcia, D., Bates, L. M., Osypuk, T. L., \& McArdle, N. (2010). The effect of immigrant generation and duration on self-rated health among US adults 2003-2007. Social Science \& Medicine, 71(6), 1161-1172. 
Alang, S. M., McCreedy, E. M., \& McAlpine, D. D. (2015). Race, ethnicity, and self-rated health among immigrants in the United States. Journal of Racial and Ethnic Health Disparities, 2, 565-572.

An, N., Cochran, S. D., Mays, V. M., \& McCarthy, W. J. (2008). Influence of American acculturation on cigarette smoking behaviors among Asian American subpopulations in California. Nicotine \& Tobacco Research, 10(4), 579-587.

Bauer, A. M., Chen, C. N., \& Alegria, M. (2010). English language proficiency and mental health service use among Latino and Asian Americans with mental disorders. Medical Care, 48(12), 1097-1104.

Berry, J. W. (1970). Marginality, stress, and ethnic identification in an acculturated aboriginal community. Journal of Cross-Cultural Psychology, 1, 239-252.

Berry, J. W. (2003). Conceptual approaches to acculturation. In K. M. Chun, P. B. Organista, \& G. Marin (Eds.), Acculturation: Advances in theory, measurement, and applied research (pp. 17-37). Washington, DC: American Psychological Association.

Berry, J. W., \& Sabatier, C. (2010). Acculturation, discrimination, and adaptation among second generation immigrant youth in Montreal and Paris. International Journal of Intercultural Relations, 34, 191-207.

Berry, J. W., \& Sam, D. L. (2016). Theoretical perspectives. In D. L. Sam \& J. W. Berry (Eds.), The Cambridge handbook of acculturation psychology (pp. 11-29). New York: Cambridge University Press.

Bulut, E., \& Gayman, M. D. (2016). Acculturation and self-rated mental health among Latino and Asian immigrants in the United States: A latent class analysis. Journal of Immigrant and Minority Health, 18, 836-849.

Chappell, N. L. (2003). Correcting cross-cultural stereotypes: Aging in Shanghai and Canada. Journal of Cross-Cultural Gerontology, 18(2), 127-147.

Choi, J. Y. (2012). Prevalence of overweight and obesity among US immigrants: Results of the 2003 New Immigrant Survey. Journal of Immigrant and Minority Health, 14, 1112-1118.

Chou, C. F., Johnson, P. J., \& Blewett, L. A. (2010). Immigration and selected indicators of health status and healthcare utilization among the Chinese. Journal of Immigrant and Minority Health, 12, 470-479.

Chung, H., \& Epstein, N. B. (2014). Perceived racial discrimination, acculturative stress, and psychological distress among Asian immigrants: The moderating effects of support and interpersonal strain from a partner. International Journal of Intercultural Relations, 42, 129-139.

Colby, S. L., \& Ortman, J. M. (2014). Projections of the Size and Composition of the U.S. population: 2014 to 2060. Current Population Reports. U.S. Census Bureau.https://www.census.gov/content/ dam/Census/library/publications/2015/demo/p25-1143.pdf. Accessed 9 August 2020.

Costigan, C. L., \& Koryzma, C. M. (2011). Acculturation and adjustment among immigrant Chinese parents: Mediating role of parenting efficacy. Journal of Counseling Psychology, 58(2), 183-196.

DeVylder, J. E., Oh, H. Y., Yang, L. H., Cabassa, L. J., Chen, F., \& Lukens, E. P. (2013). Acculturative stress and psychotic-like experiences among Asian and Latino immigrants to the United States. Schizophrenia Research, 150(1), 223-228.

Emmelin, M., Weinehall, L., Stegmayr, B., Dahlgren, L., Stenlund, H., \& Wall, S. (2003). Self-rated ill-health strengthens the effect of biomedical risk factors in predicting stroke, especially for men-An incident case referent study. Journal of Hypertension, 21(5), 887-896.

Ferguson, G. M., \& Bornstein, M. H. (2012). Remote acculturation: The "Americanization" of Jamaican Islanders. International Journal of Behavioral Development, 36(3), 167-177.

Ferraro, K. F., \& Kelley-Moore, J. A. (2001). Self-rated health and mortality among Black and White adults: Examining the dynamic evaluation thesis. Journal of Gerontology, 56B(4), S195-S205.

Frisbie, W. P., Cho, Y., \& Hummer, R. A. (2001). Immigration and the health of Asian and Pacific Islander adults in the United States. American Journal of Epidemiology, 153(4), 372-380.

Gee, G. C., Spencer, M. S., Chen, J., \& Takeuchi, D. (2007). A nationwide study of discrimination and chronic health conditions among Asian Americans. American Journal of Public Health, 97(7), 1275-1282.

Gee, G. C., Walsemann, K. M., \& Takeuchi, D. T. (2010). English proficiency and language preference: Testing the equivalence of two measures. American Journal of Public Health, 100(3), $563-569$.

Gee, G. C., de Castro, A. B., Crespi, C., Wang, M., Hing, A., Bacong, A., \& Llave, K. (2019). Preacculturation as a risk factor for obesity: Findings from the Health of Philippine Emigrants Study (HoPES). SSM-Population Health, 9, 100482. 
Gong, F., Xu, J., \& Takeuchi, D. T. (2012). Beyond conventional socioeconomic status: Examining subjective and objective social status with self-reported health among Asian immigrants. Journal of Behavioral Medicine, 35, 407-419.

Gorman, B. K., Read, J. G., \& Krueger, P. M. (2010). Gender, acculturation, and health among Mexican Americans. Journal of Health and Social Behavior, 51(4), 440-457.

Gorman, B. K., Lariscy, J. T., \& Kaushik, C. (2014). Gender, acculturation, and smoking behavior among U.S. Asian and Latino immigrants. Social Science \& Medicine, 106, 110-118.

Gorman, B. K., Novoa, C., \& Kimbro, R. T. (2016). Migration decisions, acculturation, and overweight among Asian and Latino immigrant adults in the United States. International Migration Review, 50(3), 728-757.

Hahm, H. C., Ozonoff, A., Gaumond, J., \& Sue, S. (2010). Perceived discrimination and health outcomes: A gender comparison among Asian-Americans nationwide. Women's Health Issues, 20(5), 350-358.

Hirschman, C. (1983). America's melting pot reconsidered. Annual Review of Sociology, 9, 397-423.

Hwang, W. C., \& Ting, J. Y. (2008). Disaggregating the effects of acculturation and acculturative stress on the mental health of Asian Americans. Cultural Diversity and Ethnic Minority Psychology, 14(2), 147-154.

Idler, E., Leventhal, H., McLaughlin, J., \& Leventhal, E. (2004). In sickness but not in health: Self-ratings, identity, and mortality. Journal of Health and Social Behavior, 45(3), 336-356.

Jasti, S., Lee, C. H., \& Doak, C. (2011). Gender, acculturation, food patterns, and overweight in Korean immigrants. American Journal of Health Behavior, 35(6), 734-745.

John, D. A., de Castro, A. B., Martin, D. P., Duran, B., \& Takeuchi, D. T. (2012). Does an immigrant health paradox exist among Asian Americans? Associations of nativity and occupational class with self-rated health and mental disorders. Social Science \& Medicine, 75(12), 2085-2098.

Jonnalagadda, S. S., \& Diwan, S. (2005). Health behaviors, chronic disease prevalence and self-rated health of older Asian Indian immigrants in the U.S. Journal of Immigrant Health, 7(2), 75-83.

Jylhä, M. (2009). What is self-rated health and why does it predict mortality? Towards a unified conceptual model. Social Science \& Medicine, 69(3), 307-316.

Kang, S. Y., Howard, D., Kim, J., Payne, J. S., Wilton, L., Kim, W., \& Maramba, D. (2010). English language proficiency and lifetime mental health service utilization in a national representative sample of Asian Americans in the USA. Journal of Public Health, 32(3), 431-439.

Kim, K. C., Kim, S., \& Hurh, W. M. (1991). Filial piety and intergenerational relationship in Korean immigrant families. International Journal of Aging and Human Development, 33(3), 233-245.

Kim, G., Worley, C. B., Allen, R. S., Vinson, L., Crowther, M. R., Parmelee, P., \& Chiriboga, D. A. (2011). Vulnerability of older Latino and Asian immigrants with limited English proficiency. Journal of the American Geriatrics Society, 59(7), 1246-1252.

Kimbro, R. T., Gorman, B. K., \& Schachter, A. (2012). Acculturation and self-rated health among Latino and Asian immigrants to the United States. Social Problems, 59(3), 341-363.

Lam, J., Yip, T., \& Gee, G. (2012). The physical and mental health effects of age of immigration, age, and perceived difference in social status among first generation Asian Americans. Asian American Journal of Psychology, 3(1), 29-43.

Lauderdale, D. S., \& Rathouz, P. J. (2000). Body mass index in a US national sample of Asian Americans: Effects of nativity, years since immigration and socioeconomic status. International Journal of Obesity, 24, 1188-1194.

Lee, S., O’Neill, A. H., Ihara, E. S., \& Chae, D. H. (2013). Change in self-reported health status among immigrants in the United States: Associations with measures of acculturation. PLoS One. https:// doi.org/10.1371/journal.pone.0076494.

Leu, J., Walton, E., \& Takeuchi, D. (2011). Contextualizing acculturation: Gender, family, and community reception influences on Asian immigrant mental health. American Journal of Community Psychology, 48, 168-180.

Lommel, L. L., \& Chen, J. L. (2016). The relationship between self-rated health and acculturation in Hispanic and Asian adult immigrants: A systematic review. Journal of Immigrant and Minority Health, $18,468-478$.

Lopez-Gonzalez, L., Aravena, V. C., \& Hummer, R. A. (2005). Immigrant acculturation, gender and health behavior: A research note. Social Forces, 84(1), 577-589.

Lubben, J., \& Becerra, R. (1987). Social support among Black, Mexican, and Chinese elderly. In D. Gelfand \& C. Barresi (Eds.), Ethnic dimensions of aging (pp. 130-144). New York: Springer.

Ma, G. X., Tan, Y., Toubbeh, J. I., Su, X., Shive, S. E., \& Lan, Y. (2004). Acculturation and smoking behavior in Asian-American populations. Health Education Research, 19(6), 615-625. 
Magidson, J., \& Vermunt, J. K. (2004). Latent class analysis. In D. Kaplan (Ed.), The Sage handbook of quantitative methodology for the social sciences (pp. 175-198). Thousand Oaks, California: Sage Publications.

May, M., Lawlor, D. A., Brindle, P., Patel, R., \& Ebrahim, S. (2006). Cardiovascular disease risk assessment in older women: Can we improve on Framingham? British Women's Heart and Health prospective cohort study. Heart, 92, 1396-1401.

Min, P. G. (1992). The structure and social functions of Korean immigrant churches in the United States. International Migration Review, 26(4), 1370-1394.

Mui, A. C., \& Kang, S. Y. (2006). Acculturation stress and depression among Asian immigrant elders. Social Work, 51(3), 243-255.

National Geographic. (2018). Asian-Americans Make Up Most of the New U.S. Immigrant Population. Published article on September 14th.

Park, Y., Neckerman, K. M., Quinn, J., Weiss, C., \& Rundle, A. (2008). Place of birth, duration of residence, neighborhood immigrant composition and body mass index in New York City. International Journal of Behavioral Nutrition and Physical Activity, 5, 19.

Park, S. Y., Anastas, J., Shibusawa, T., \& Nguyen, D. (2014). The impact of acculturation and acculturative stress on alcohol use across Asian immigrant subgroups. Substance Use \& Misuse, 49(8), 922-931.

Pew Research Center. (2017). Key Facts about Asian Americans, A Diverse and Growing Population. https://www.pewresearch.org/fact-tank/2017/09/08/key-facts-about-asian-americans. Accessed 9 August 2020.

Pew Research Center. (2019). Key Facts about Asian Origin Groups in the U.S. https://www.pewresearc h.org/fact-tank/2019/05/22/key-facts-about-asian-origin-groups-in-the-u-s/. Accessed 9 August 2020.

Ro, A., Geronimus, A., Bound, J., Griffith, D., \& Gee, G. (2015). Cohort and duration patterns among Asian immigrants: Comparing trends in obesity and self-rated health. Biodemography and Social Biology, 61(1), 65-80.

Schwartz, S. J., \& Zamboanga, B. L. (2008). Testing Berry's model of acculturation: A confirmatory latent class approach. Cultural Diversity and Ethnic Minority Psychology, 14(4), 275-285.

Shadbolt, B., Barresi, J., \& Craft, P. (2002). Self-rated health as a predictor of survival among patients with advanced cancer. Journal of Clinical Oncology, 20(10), 2514-2519.

Shin, J. K. (2002). Help-seeking behaviors by Korean immigrants for depression. Issues in Mental Health Nursing, 23, 461-476.

Singh, G. K., \& Lin, S. C. (2013). Dramatic increases in obesity and overweight prevalence among Asian subgroups in the United States, 1992-2011. ISRN Preventive Medicine, 2013, 1-12.

Singh, G. K., Siahpush, M., Hiatt, R. A., \& Timsina, L. R. (2011). Dramatic increases in obesity and overweight prevalence and body mass index among ethnic-immigrant and social class groups in the United States, 1976-2008. Journal of Community Health, 36, 94-110.

Snauwaert, B., Soenens, B., Vanbeselaere, N., \& Boen, F. (2003). When integration does not necessarily imply integration: Different conceptualizations of acculturation orientations lead to different classifications. Journal of Cross-Cultural Psychology, 3, 231-239.

Sommerlad, E., \& Berry, J. W. (1970). The role of ethnic identification in distinguishing between attitudes towards assimilation and integration. Human Relations, 23, 23-29.

Torres, L., Driscoll, M. W., \& Voell, M. (2012). Discrimination, acculturation, acculturative stress, and Latino psychological distress: A moderated mediational model. Cultural Diversity and Ethnic Minority Psychology, 18(1), 17-25.

Tran, T. V., Nguyen, D., Chan, K., \& Nguyen, T.-N. (2013). The association of self-rated health and lifestyle behaviors among foreign-born Chinese, Korean, and Vietnamese Americans. Quality of Life Research, 22(2), 243-252.

Tsoh, J. Y., Sentell, T., Gildengorin, G., Le, G. M., Chan, E., Fung, L. C., et al. (2016). Healthcare communication barriers and self-rated health in older Chinese American immigrants. Journal of Community Health, 41(4), 741-752.

Tummala-Narra, P., Alegria, M., \& Chen, C. N. (2012). Perceived discrimination, acculturative stress, and depression among South Asians: Mixed findings. Asian American Journal of Psychology, 3(1), $3-16$.

Veenstra, G. (2011). Race, gender, class, and sexual orientation: Intersecting axes of inequality and selfrated health in Canada. International Journal for Equity in Health, 10, 3. 
Wong, S. T., Yoo, G. J., \& Stewart, A. L. (2005). Examining the types of social support and the actual sources of support in older Chinese and Korean immigrants. International Journal of Aging and Human Development, 61(2), 105-121.

Wong, S. T., Yoo, G. J., \& Stewart, A. L. (2007). An empirical evaluation of social support and psychological well-being in older Chinese and Korean immigrants. Ethnicity and Health, 12(1), 43-67.

Wu, S., Wang, R., Zhao, Y., Ma, X., Wu, M., Yan, X., \& He, J. (2013). The relationship between selfrated health and objective health status: A population-based study. BMC Public Health, 13, 320.

$\mathrm{Xu}$, L., \& Chi, I. (2013). Acculturative stress and depressive symptoms among Asian immigrants in the United States: The roles of social support and negative interaction. Asian American Journal of Psychology, 4(3), 217-226.

Zhang, W. (2012). Negative social exchanges, acculturation-related factors, and mental health among Asian Americans. A Journal of the BSA MedSoc Group, 6(2), 12-29.

Zhang, W., \& Hong, S. (2013). Perceived discrimination and psychological distress among Asian Americans: Does education matter? Journal of Immigrant and Minority Health, 15, 932-943.

Zhang, W., Hong, S., Takeuchi, D. T., \& Mossakowski, K. N. (2012). Limited English proficiency and psychological distress among Latinos and Asian Americans. Social Science \& Medicine, 75(6), 1006-1014.

Publisher's Note Springer Nature remains neutral with regard to jurisdictional claims in published maps and institutional affiliations. 